Article

\title{
Advanced Treatment of Phosphorus Pesticide Wastewater Using an Integrated Process of Coagulation and Ozone Catalytic Oxidation
}

\author{
Shengping Cao ${ }^{1,2}$, Lei Chen ${ }^{2, *}$, Minyan Zhao ${ }^{3}$, Ankang Liu ${ }^{3}$, Mingxiu Wang ${ }^{3}$ and Yongjun Sun ${ }^{4, *}$ (D) \\ 1 Ningxia Baichuan New Materials Co., Ltd., Yinchuang 750411, China; cspmanager123@163.com \\ 2 College of Environmental Science and Engineering, Nanjing Tech University, Nanjing 211816, China \\ 3 Nanjing Water Purification Environmental Research Institute Co., Ltd., Nanjing 211100, China; \\ zhaominyan.614@163.com (M.Z.); lakyx2@126.com (A.L.); njwprhj@126.com (M.W.) \\ 4 College of Urban Construction, Nanjing Tech University, Nanjing 211816, China \\ * Correspondence: chenlei@njtech.edu.cn (L.C.); sunyongjun@njtech.edu.cn (Y.S.)
}

check for

updates

Citation: Cao, S.; Chen, L.; Zhao, M.; Liu, A.; Wang, M.; Sun, Y. Advanced Treatment of Phosphorus Pesticide Wastewater Using an Integrated Process of Coagulation and Ozone Catalytic Oxidation. Catalysts 2022, 12, 103. https://doi.org/10.3390/ catal12010103

Academic Editors: Wen Da Oh, Yueping Bao and Chong Wang

Received: 20 October 2021

Accepted: 17 November 2021

Published: 17 January 2022

Publisher's Note: MDPI stays neutral with regard to jurisdictional claims in published maps and institutional affiliations.

Copyright: (C) 2022 by the authors. Licensee MDPI, Basel, Switzerland. This article is an open access article distributed under the terms and conditions of the Creative Commons Attribution (CC BY) license (https:// creativecommons.org/licenses/by/ $4.0 /)$.

\begin{abstract}
Conventional pretreatment and secondary biochemical treatment are ineffective methods for removing phosphorus from phosphorus-containing pesticide wastewater. In this study, coagulation-coupled ozone catalytic oxidation was used to treat secondary biochemical tailwater of phosphorus-containing pesticide wastewater thoroughly. The effects of the coagulant type, coagulant dosage, coagulant concentration, wastewater $\mathrm{pH}$, stirring rate, and stirring time on the removal efficiency of chemical oxygen demand (COD), total phosphorus (TP), and chromaticity were investigated during coagulation. When the dosage of the coagulant PAFS was equal to $100 \mathrm{mg} / \mathrm{L}$, the concentration of the coagulant, $\mathrm{pH}$, stirring rate, and stirring time were $5 \mathrm{wt} \%, 8,100 \mathrm{rpm}$, and $5 \mathrm{~min}$, respectively, and the removal rates of $\mathrm{COD}, \mathrm{TP}$, and chroma in wastewater reached the maximum value of $17.6 \%, 86.8 \%$, and $50.0 \%$, respectively. Effluent after coagulation was treated via ozone catalytic oxidation. When the respective ozone dosage, $\mathrm{H}_{2} \mathrm{O}_{2}$ dosage, catalyst dosage, and reaction time were $120 \mathrm{mg} / \mathrm{L}, 0.1 \mathrm{vt} \%$, $10 \mathrm{wt} \%$, and $90 \mathrm{~min}$, residual COD and chromaticity of the final effluent were $10.3 \mathrm{mg} / \mathrm{L}$ and 8 , respectively. The coagulation-coupled ozone catalytic oxidation process has good application prospects in the treatment of secondary biochemical tailwater from phosphorus-containing pesticide wastewater.
\end{abstract}

Keywords: coagulation; ozone catalytic oxidation; advanced treatment; phosphorus pesticide wastewater; biochemical tailwater

\section{Introduction}

The abuse of pesticides worldwide has caused severe environmental problems and widespread concern [1]. As the main agricultural agent, phosphorus-containing pesticides are widely used in local and foreign agricultural production because of their wide killing range, significant effect, and high pest lethality [2]. Raw materials, such as phosphorus trichloride, chloroacetic acid, methanol, and toluene, are primarily used in the production of phosphorus-containing pesticides with dimethyl phosphite and phosphorothioate as the principal intermediates [3]. Production wastewater is characterized by its high toxicity, high salt content, foul odor, and poor biodegradability [4]. The rapid development of agriculture, increasing use of phosphorus-containing pesticides, and large amounts of phosphorus-containing wastewater generated in the production process of pesticides have discharged harmful substances, which can be absorbed by passive plants into water bodies, such as lakes, rivers, and oceans [5]. These substances seriously threaten human life and health through their enrichment in the food chain. The discharge of phosphorus-containing wastewater increases the load of nutrients in the water body, easily causes eutrophication of water bodies, and threatens the ecological environment [6]. Therefore, effective degradation 
techniques or methods are necessary to alleviate the pollution of phosphorus-containing pesticide wastewater in the environment.

Activated sludge, adsorption, and wet catalytic oxidation are commonly used treatment methods for phosphorus-containing pesticide wastewater [7]. Activated sludge is an effective sewage treatment that can remove soluble and colloidal biochemical organic matter from sewers [8]. However, phosphorus-containing pesticide wastewater can eliminate microorganisms in the sludge, cause a poor treatment effect, and has a high treatment cost because of its complex composition and high toxicity [9]. The adsorption method uses the porous structure and large specific surface area of adsorbents to adsorb pollutants in wastewater. Activated carbon and synthetic macroporous adsorption resins are commonly used adsorbents in pesticide wastewater treatment [10]. However, general adsorbents are expensive and have a poor treatment effect due to the strong polarity and water solubility of organic phosphate ester compounds in wastewater. Moreover, problems in the industrial application of adsorbents in recovery and regeneration methods still persist [11]. The wet oxidation method uses oxygen in its gaseous state to oxidize organic matter in pesticide wastewater to $\mathrm{CO}_{2}$ and $\mathrm{H}_{2} \mathrm{O}$ under high temperature and pressure condition. Wet catalytic oxidation can effectively treat the issues of high concentration, biological refractory, and toxicity of harmful pesticide wastewater [12]. Organic phosphorus in wastewater is degraded and converted into inorganic phosphorus. The promotion and use of the wet oxidation method in actual projects are limited because of the harsh reaction conditions that have high equipment requirements involving complicated operations and large investment for equipment cost [13].

Coagulation technology has been widely used in domestic sewage and industrial wastewater treatment for wastewater pretreatment and advanced treatment in combination with other processes. The coagulation method can effectively remove suspended solids and achieve the separation of pollutants. The treatment efficiency for Ni containing electroplating wastewater was comparatively evaluated through ozone oxidation $(42 \% \mathrm{Ni}$ and $26 \%$ Cr removal efficiencies) and coagulation process (98\% and $99 \%$ removal of $\mathrm{Ni}$ and Cr) [14]. The coagulant-dependent action process includes coagulation and flocculation. Coagulants can reduce the stability of the suspended colloidal particles in water, cause colloidal particles to agglomerate with one another, and form many small alum flowers [15]. Alum flowers are aggregated to form large flocs through adsorption, bridging, and sweeping [16]. Ozone catalytic oxidation, a kind of advanced oxidation method, is widely used in the advanced treatment of wastewater with complex components for the promotion of ozone decomposition through the action of a catalyst to form hydroxyl radicals with strong oxidation [17]. For example, hydroxyl radicals in cocoa undergo a chain reaction with phosphorus in phosphorus-containing pesticide wastewater. $\mathrm{P}=\mathrm{S}$ bonds in oxygen atoms or hydroxyl radicals of phosphorus-containing pesticides are oxidized into $\mathrm{P}=\mathrm{O}$ bonds, which change the molecular structure of the substance for the effective degradation and decomposition of pesticides [18]. In addition, the ozone catalytic oxidation method can not only rapidly degrade organic matter but also improve the biodegradability, decolorization, deodorization, and sterilization of wastewater [19].

In this study, coagulation coupled with ozone catalytic oxidation was used to treat the biochemical tailwater of phosphorus-containing pesticide wastewater thoroughly. The effects of coagulant type, coagulant dosage, coagulant concentration, $\mathrm{pH}$, stirring rate, and stirring time on COD, TP, and color were explored during coagulation. The wastewater treated under the optimal conditions of coagulation was then catalyzed with ozone. The effects of ozone addition, $\mathrm{H}_{2} \mathrm{O}_{2}$ addition, catalyst addition, and reaction time on $\mathrm{COD}$ and chroma removal efficiency were investigated during ozone catalytic oxidation. 


\section{Results}

\subsection{Coagulation Treatment of Biochemical Tailwater from Phosphorus-Containing Pesticide} Wastewater

\subsubsection{Effect of Coagulant Type on Coagulation Performance}

Figure 1 shows that the coagulant $\mathrm{CaCl}_{2}$ has the worst removal effect on TP with a removal rate of $72.9 \%$. Similarly, the TP removal efficiency obtained by inorganic polymer coagulants (PAC, $\mathrm{AlCl}_{3}, \mathrm{PFS}, \mathrm{Fe}_{2}\left(\mathrm{SO}_{4}\right)_{3}, \mathrm{PAFC}$, and PAFS) is better than that by inorganic low molecular coagulants. Among the inorganic polymer coagulants, PAFS demonstrated an excellent removal effect with a removal rate of up to $17.0 \%$. PAC, $\mathrm{AlCl}_{3}, \mathrm{PFS}, \mathrm{Fe}_{2}\left(\mathrm{SO}_{4}\right)_{3}$, $\mathrm{CaCl}_{2}$, and PAFC have a relatively low effect on the removal of chromaticity. The excellent removal efficiency of PAFS on chromaticity is exhibited at the removal rate of $50.0 \%$.

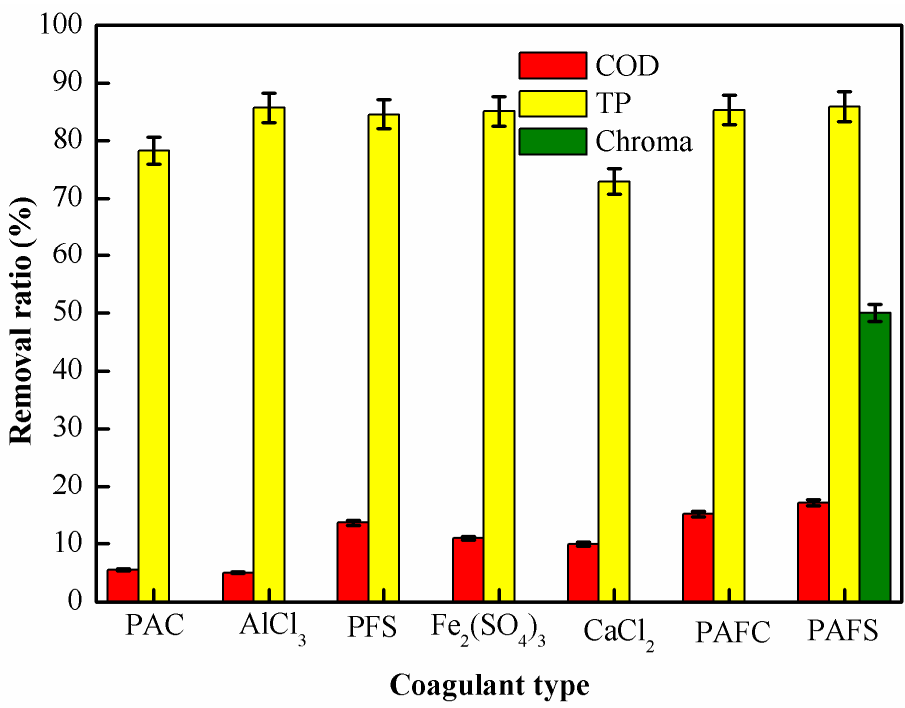

Figure 1. Effect of coagulant type on coagulation performance.

PAFS shows superior performance in removing COD, TP, and chroma because of its longer molecular chain and more cationic functional groups compared with other inorganic low molecular coagulants. PAFS can provide enough adsorption sites for adsorbing pollutants [20]. The simultaneous action of adsorption bridging, precipitation net trapping, and charge neutralization in the destabilization process of PAFS treatment of wastewater is beneficial to the formation of flocs. Compared with PAFC, PAFS is a mixture of two aluminum-iron salts with a better aluminum-iron ratio [21]. A large amount of high-charge and high-polymerization aluminum-iron multinuclear complex ions or metal oxide gels will be produced during PAFS hydrolysis of substances, and aluminum-iron polynuclear complex ions or metal oxide gels produce adsorption bridging and sweeping sedimentation of destabilized particles that cause the pollutants in the water to settle and further improve the treatment effect of wastewater [22].

\subsubsection{Effect of $\mathrm{pH}$ on Coagulation Performance}

Figure 2 shows the effect of $\mathrm{pH}$ on the coagulation performance. The removal rate of COD increased with increasing $\mathrm{pH}$. When $\mathrm{pH}=9$, the removal rate of COD reached the maximum value of $17.0 \%$. The removal rate of TP first increased with $\mathrm{pH}$ and then gradually stabilized and achieved the maximum value of $85.0 \%$ when $\mathrm{pH}=9$. When $\mathrm{pH}<6$, the degradation of wastewater color was unaffected by PAFS. When $6<\mathrm{pH}<8$, the removal rate of chromaticity increased rapidly with the increase in $\mathrm{pH}$, and the removal efficiency reached the maximum value of $75.0 \%$ at $\mathrm{pH}=8$. When $\mathrm{pH}$ was between 8 and 10 , the removal rate of color was unaffected by the $\mathrm{pH}$ changes. 


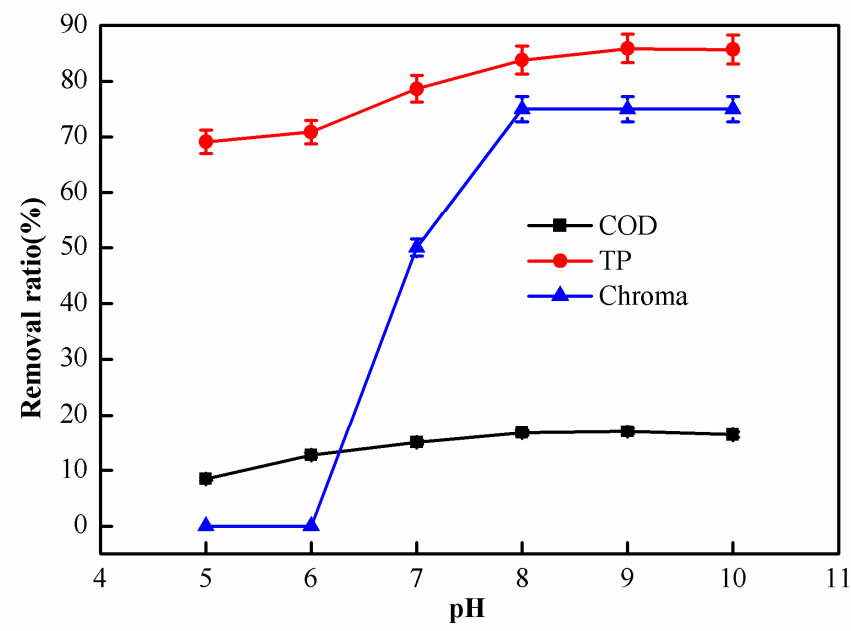

Figure 2. Effect of $\mathrm{pH}$ on coagulation performance.

The degree of PAFS hydrolysis and the form of phosphorus in wastewater are related to the $\mathrm{pH}$ level. A low $\mathrm{pH}$ value inhibits the hydrolysis of PAFS primarily in the form of $\mathrm{A}^{3+}$ and $\mathrm{Fe}^{3+}$ ions with high charge and low polymerization degree and does not contribute to the action mechanisms of net sweeping and adsorption bridging [23]. Hence, the removal efficiency of COD, TP, and chroma in wastewater is low. The corresponding degree of hydrolysis of PAFS increases with increasing $\mathrm{pH}$. Phosphorus in water exists in the form of $\mathrm{H}_{2} \mathrm{PO}_{4}{ }^{-}$and $\mathrm{HPO}_{4}{ }^{2-}$. When $\mathrm{pH}$ is too high, high $\mathrm{OH}^{-}$concentrations will likely form electrostatic repulsion reactions [24,25], which directly affect the charge adsorption process in flocculation, which in turn stops the increase in the wastewater removal rate. In summary, the optimal $\mathrm{pH}$ for PAFS coagulation is 8 .

\subsubsection{Effect of PAFS Dosage on Coagulation Performance}

The effect of PAFS dosage on coagulation performance is illustrated in Figure 3 . The removal efficiency of COD increased slowly with the increase in PAFS dosage. When the dosage was equal to $200 \mathrm{mg} / \mathrm{L}$, the removal rate reached the maximum value of $17.8 \%$. With the increase in PAFS dosage, the removal rate of TP first increased rapidly and then slowed down. When the dosage was equal to $250 \mathrm{mg} / \mathrm{L}$, the maximum removal rate of TP reached the maximum value of $96.0 \%$. When the PAFS dosage was greater than $50 \mathrm{mg} / \mathrm{L}$, the removal rate of chromaticity first increased, stabilized, decreased, and then stabilized with the increase in PAFS dosage. When the dosage of PAFS was equal to $100 \mathrm{mg} / \mathrm{L}$, the removal rate of chromaticity reached the maximum value of $75.0 \%$.

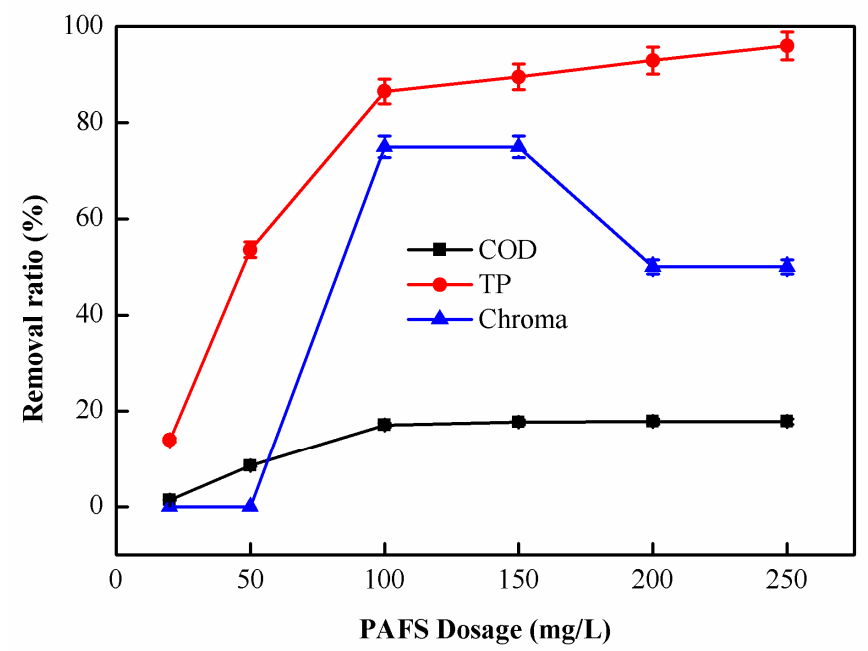

Figure 3. Effect of PAFS dosage on coagulation performance. 
The action mechanism of coagulant PAFS primarily includes adsorption bridging, net catching and sweeping, and charge neutralization. When the amount of added PAFS is too small, adsorption bridging and net trapping ability weaken, and the floc particles are small. At this time, electrical neutralization is dominant and the removal efficiency of COD, TP, and chroma is low. The increase in adsorption bridging and net capturing capabilities with the increasing amount of added PAFS increases the wastewater removal efficiency [26]. When the dosage is too large, PAFS primarily exhibits the function of adsorption and bridging. According to the principle of colloidal protection, the colloidal particles formed through PAFS hydrolysis will be hindered by the repulsive force derived from the PAFS molecules This repulsive force may either be due to the compressive deformation between the colloidal particles formed by the hydrolysis of PAFS to generate repulsive potential energy or the electrical repulsive force between PAFS molecules [27]. In summary, the optimal dosage of coagulant PAFS is $100 \mathrm{mg} / \mathrm{L}$.

\subsubsection{Effect of PAFS Concentration on Coagulation Performance}

The effect of PAFS concentration on coagulation performance is illustrated in Figure 4. The removal rate of COD gradually decreases with the increase in PAFS concentration. The COD removal effect reaches the maximum when the concentration of PAFS is equal to $5 \mathrm{wt} \%$ with a corresponding removal rate of $16.9 \%$. The removal rate of TP gradually decreases with the increase in the concentration of coagulant PAFS. When the concentration of PAFS is equal to $1.0 \mathrm{wt} \%$, the removal rate reaches the maximum value at $87.7 \%$. When the concentration of PAFS is $1-5 \mathrm{wt} \%$, the removal efficiency of chromaticity is stable at $75.0 \%$. When the concentration is greater than $5 \mathrm{wt} \%$, the removal rate of chromaticity reduces significantly with the increase in PAFS concentration. When the concentration of PAFS is equal to $12 \mathrm{wt} \%$, the chroma removal rate reaches 0 .

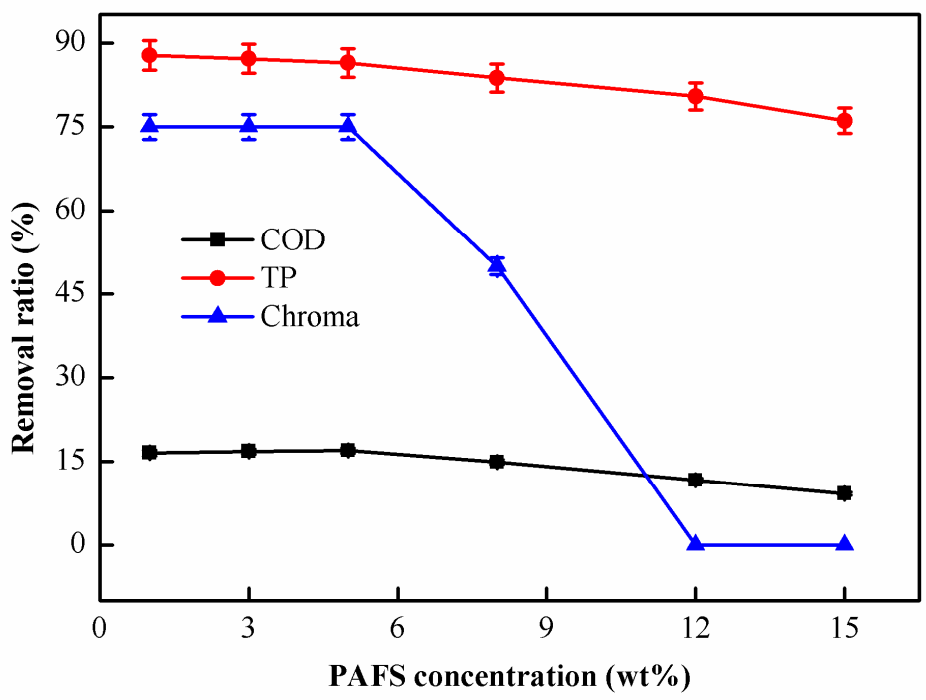

Figure 4. Effect of PAFS concentration on coagulation performance.

The appropriate concentration of PAFS can improve the treatment effect. Given that PAFS is a cationic coagulant, $\mathrm{Fe}^{3+}$ and $\mathrm{Al}^{3+}$, which generate positive charges after hydrolysis, can react with the negatively charged pollutants in wastewater to remove COD, chroma, and TP in wastewater when the dosage of the coagulant PAFS is within a suitable range. When the concentration of added PAFS is too high, the number of positive charges in water is remarkably higher than that of negative charges [28]. Electrostatic repulsion will occur when too many positive charges exist, affect the neutralization of the charge, and thus worsen the treatment effect. In summary, the optimal concentration of the coagulant PAFS in the coagulation test is $5 \mathrm{wt} \%$. 


\subsubsection{Effect of Stirring Speed on Coagulation Performance}

Figure 5 shows the effect of stirring speed on the coagulation performance. When the stirring rate is less than $100 \mathrm{rpm}$, the COD removal rate first increases and then decreases with the increasing stirring rate. When the stirring rate is equal to $100 \mathrm{rpm}$, the COD and TP removal rates reach the maximum and optimal values of $17.6 \%$ and $87.6 \%$, respectively. When the stirring rate is between 20 and $100 \mathrm{rpm}$, the removal rate of TP is slightly affected by the stirring rate. When the stirring rate is greater than $100 \mathrm{rpm}$, the TP removal rate reduces slowly with the increasing stirring rate. When the stirring rate is between 20 and $120 \mathrm{rpm}$, the removal rate of chromaticity is stabilized at $75.0 \%$ but decreases to $50.0 \%$ when the stirring rate continues to increase.

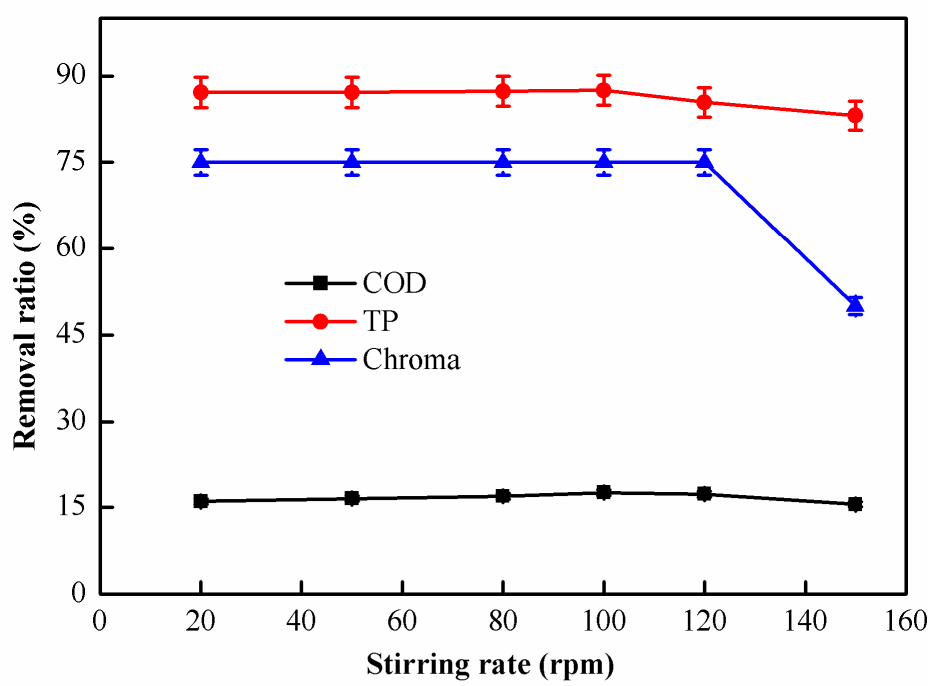

Figure 5. Effect of stirring speed on coagulation performance.

The appropriate stirring rate can lead to good coagulation performance. PAFS typically removes COD, TP, and chroma in water bodies through electric neutralization and adsorption bridging [29]. When the stirring speed is too slow, PAFS can only partially come into contact with the pollutants in the sewage, and the weakened electrical neutralization and adsorption bridging effect of the coagulant will result in a poor coagulation effect [30]. Increasing the stirring speed to an appropriate rate can improve the collision efficiency of PAFS hydrolysis, form highly charged aluminum-iron polynuclear complex ions and pollutants [31], and accelerate the formation of flocs. When the stirring speed is too fast, the flocs will be broken by the shearing force in the water and the weakened adsorption bridging of the coagulant and net sweeping, and the sweeping effect is not conducive to coagulation. In summary, the optimal stirring rate for the coagulation test is equal to $100 \mathrm{rpm}$.

\subsubsection{Effect of Stirring Time on Coagulation Performance}

Figure 6 illustrates that the COD removal rate first increases and then gradually decreases with the increase in stirring time. When the stirring time was $5 \mathrm{~min}$, the removal rate reached the maximum value of $17.6 \%$. The removal rate of TP slowly increased and then decreased with the increasing stirring time. When the stirring time was $2 \mathrm{~min}$, the removal rate reached the maximum value of $87.2 \%$. The removal rate of chroma increased from $50.0 \%$ to $75.0 \%$ when the stirring time was increased from $1 \mathrm{~min}$ to $2 \mathrm{~min}$. The removal rate of chromaticity is unaffected by the change of stirring time between 2 and $8 \mathrm{~min}$. The rate first decreased and then remained unchanged at $50.0 \%$. 


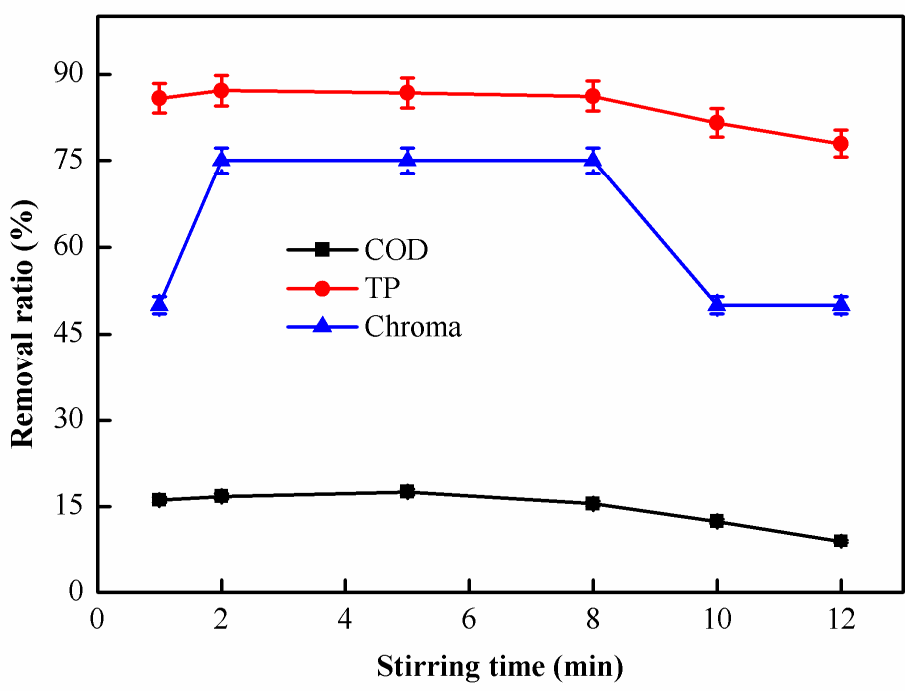

Figure 6. Effect of stirring time on coagulation performance.

When the stirring rate is constant, the stirring time generally affects the coagulation effect to a certain extent. The appropriate increase in stirring time can improve the treatment performance [32]. When the stirring time is too short, the contact between the PAFS molecules and the particulate matter in the water body is insufficient and the charge neutralization and adsorption bridging effect of PAFS is poorly exerted [33]. When the agitation time is too long, the extended shear force in the water body can separate the particulate matter that has been adsorbed by PAFS, release it into the water body again, and weaken the adsorption bridging and net sweeping effect of PAFS. If the stirring time exceeds a certain range, then the treatment efficiency of coagulation is reduced [34]. In summary, the appropriate stirring time is $5 \mathrm{~min}$.

\subsection{Ozone Catalytic Oxidation Treatment of Biochemical Tailwater from Phosphorus-Containing} Pesticide Wastewater

\subsubsection{Effect of $\mathrm{H}_{2} \mathrm{O}_{2}$ Dosage on Catalytic Oxidation Performance}

Figure 7 illustrates that the COD removal rate first increases and then decreases with the increase in $\mathrm{H}_{2} \mathrm{O}_{2}$ dosage. The COD removal rate reaches the maximum value of $41.2 \%$ at an $\mathrm{H}_{2} \mathrm{O}_{2}$ volume fraction of $0.1 \mathrm{vt} \%$. The chroma removal is unaffected by the change of $\mathrm{H}_{2} \mathrm{O}_{2}$ dosage, and the chroma removal rate is maintained at $75.0 \%$.

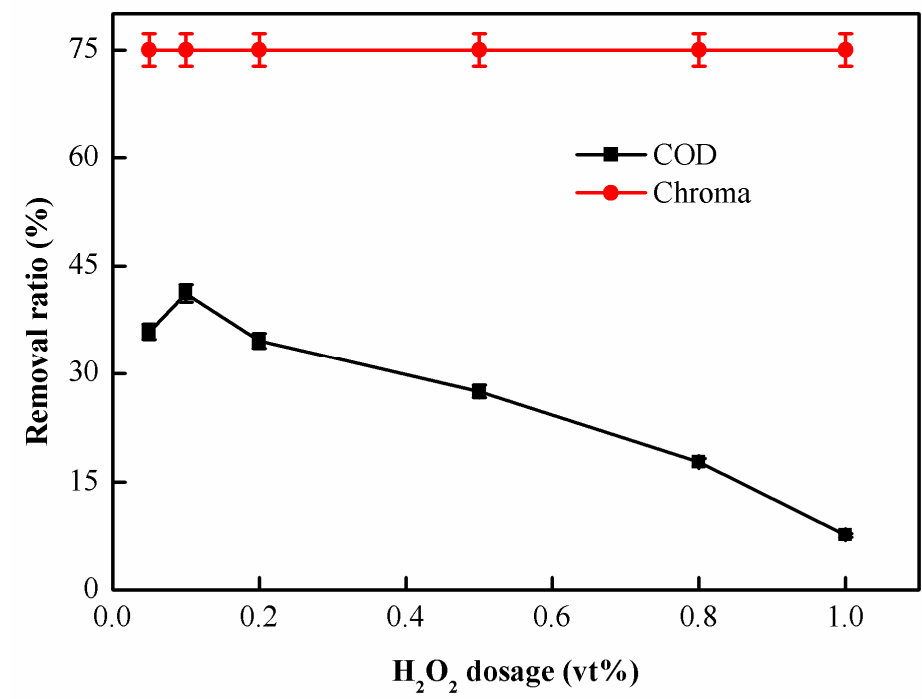

Figure 7. Effect of $\mathrm{H}_{2} \mathrm{O}_{2}$ dosage on catalytic oxidation performance. 
When the ozone dosage is fixed, the small dosage of $\mathrm{H}_{2} \mathrm{O}_{2}$ is clearly unaffected by $\mathrm{Fe}^{3+}$ in the laboratory-made iron-based catalyst and the amount of hydroxyl radicals generated by the decomposition of $\mathrm{H}_{2} \mathrm{O}_{2}$ is relatively small $[35,36]$. The appropriate increase in the amount of added $\mathrm{H}_{2} \mathrm{O}_{2}$ can improve the treatment effect to a certain extent. When the amount of added $\mathrm{H}_{2} \mathrm{O}_{2}$ is too large, the excess $\mathrm{H}_{2} \mathrm{O}_{2}$ consumes a portion of the ozone from the gas phase to the liquid phase and reduces the ozone utilization rate [37]. $\mathrm{H}_{2} \mathrm{O}_{2}$ itself is also an inhibitor of $\mathrm{OH}$ that can rapidly react with hydroxyl radicals. Therefore, a large amount of captured, quenched, and inactivated hydroxyl radicals adversely affects the degradation of organic matter in water and causes the degradation rate of COD to reduce rapidly $[38,39]$. In summary, the optimal dosage of $\mathrm{H}_{2} \mathrm{O}_{2}$ is $0.1 \mathrm{vt} \%$.

\subsubsection{Effect of $\mathrm{O}_{3}$ Dosage on Catalytic Oxidation Performance}

Figure 8 illustrates the effect of ozone dosage on the catalytic oxidation of ozone. The removal rate of COD continues to increase with the increase in ozone dosage. When the dosage of ozone is $150 \mathrm{mg} / \mathrm{L}$, the removal rate reaches the optimal value of $58.8 \%$. The generally increasing state of removal rate of chromaticity first increases, stabilizes, increases again, and then stabilizes with the increase in ozone dosage. The removal rate of chromaticity reaches its maximum value of $75.0 \%$ when the dosage of ozone is equal to $120 \mathrm{mg} / \mathrm{L}$.

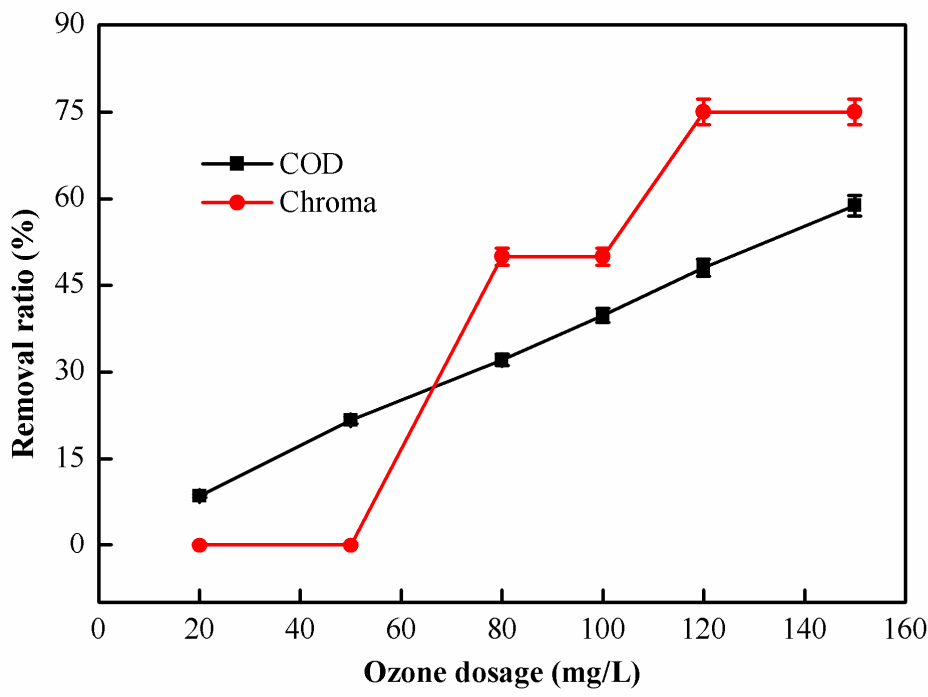

Figure 8. Effect of $\mathrm{O}_{3}$ dosage on catalytic oxidation performance.

Ozone catalytic oxidation primarily produces $\cdot \mathrm{OH}$ through ozone catalysis and oxidizes organic matter in water through $\cdot \mathrm{OH}$. Appropriately increasing the dosage of ozone can enhance the oxidation of ozone itself and increase the production of active free radicals in the reaction system $[40,41]$. However, high concentrations of ozone will also be trapped by $\cdot \mathrm{OH}$ radicals. When the ozone concentration is further increased, the reaction rates will no longer increase and then stabilize the removal rate of chroma after a period of increase. The concentration of ozone in the water is close to saturation, and the excess ozone that escapes in the form of microbubbles causes wastage of resources [42]. In summary, the optimal ozone dosage for ozone catalytic oxidation is equal to $120 \mathrm{mg} / \mathrm{L}$.

\subsubsection{Effect of Catalyst Dosage on Catalytic Oxidation Performance}

Figure 9 shows the effect of changes in catalyst dosage on the catalytic oxidation performance of ozone. When the amount of catalyst added is less than $10 \mathrm{wt} \%$, the COD removal rate increases with the increasing amount of catalyst added, to a large extent. When the amount of catalyst added is more than $10 \mathrm{wt} \%$, the COD removal rate stabilizes as the amount of catalyst added increases. The COD removal rate reached the maximum of 
$56.9 \%$ when the catalyst dosage was $25 \mathrm{wt} \%$. The removal rate of chromaticity is unaffected by the change of catalyst dosage and maintained at $75.0 \%$.

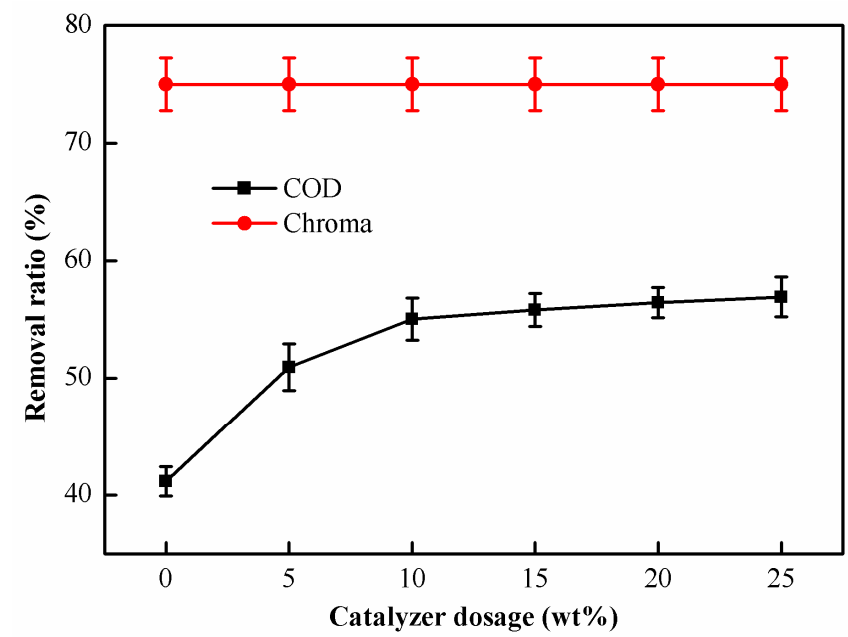

Figure 9. Effect of catalyst dosage on catalytic oxidation performance.

The increase in the amount of catalyst added increases the available active sites, remarkably increases the chance of ozone molecules colliding with the catalyst, speeds up the reaction rate of the system, and makes full use of the ozone. When the ozone concentration is constant, adding too much catalyst prevents the active sites from being fully occupied and results in the wastage of catalyst. If the dosage of iron-based catalyst is too high, then the excessive hydroxyl radicals generated can interact to form hydrogen peroxide, which weakens the effect of hydroxyl radicals and results in a stable removal rate [43]. In summary, the optimal catalyst dosage for ozone catalytic oxidation is $10 \mathrm{wt} \%$.

\subsubsection{Effect of Reaction Time on Catalytic Oxidation Performance}

The effect of reaction time on the catalytic oxidation performance of ozone is illustrated in Figure 10. When the reaction time is less than $90 \mathrm{~min}$, the COD removal rate increases with the extension of the reaction time. When the reaction time is longer than $90 \mathrm{~min}$, the removal rate of COD is slightly affected by the change of reaction time and the removal rate is stable within the range of $60.4 \%-61.8 \%$. The removal rate of chroma is increased from $50.0 \%$ at a reaction time of $10 \mathrm{~min}$ to $75.0 \%$ at $30 \mathrm{~min}$. When the reaction time is greater than $30 \mathrm{~min}$, the removal rate of chroma is maintained at $75.0 \%$.

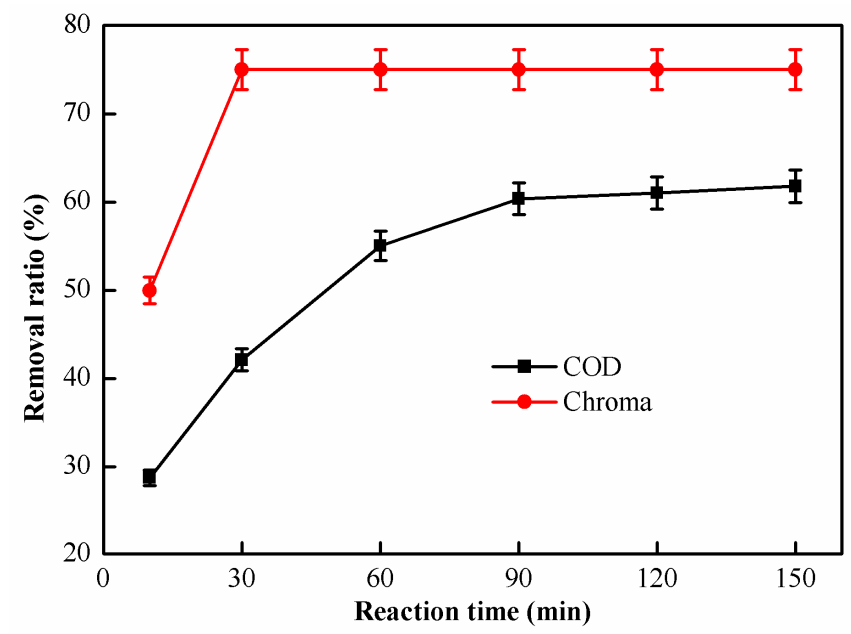

Figure 10. Effect of reaction time on catalytic oxidation performance. 
The extension of reaction time increases the residual ozone concentration in the water, the substrate of the ozone catalytic oxidation system, and removal efficiency of wastewater. When the reaction time is short, the ozone concentration in the water is very low and the substrate of the ozone catalytic oxidation reaction system is insufficient to remove pollutants in the water [44]. The ozone concentration affects the mass transfer rate of ozone in the water phase, which typically affects the ozone utilization rate. When the reaction time is too long, the accumulation of ozone in catalytic oxidation will increase, the improvement of the catalytic oxidation effect becomes increasingly difficult, and the removal rates remain stable [45]. In summary, the optimal reaction time is $90 \mathrm{~min}$.

\section{Materials and Methods}

\subsection{Materials}

Analytical-grade PAC, $\mathrm{AlCl}_{3}, \mathrm{PFS}, \mathrm{Fe}_{2}\left(\mathrm{SO}_{4}\right)_{3}, \mathrm{CaCl}_{2}, \mathrm{PAFC}$, and PAFS were purchased from Sinopharm Group Chemical Reagent Co., Ltd. (Shanghai, China). Analytical-grade concentrated hydrochloric acid, $\mathrm{NaOH}$, hydrogen peroxide, and $\mathrm{KI}$ were obtained from Nanjing Chemical Reagent Co., Ltd. (Nanjing, China). High-purity oxygen was bought from Nanjing Sanle Electronics Co., Ltd. (Nanjing, China). The iron-based catalyst used in this study was self-made in the laboratory. The actual wastewater from this experiment was collected from the second settling tank of a sewage treatment plant of a pesticide production enterprise in Jiangsu Province. The quality of the raw water is listed in Table 1.

Table 1. Raw water quality of coal chemical biochemical tailwater.

\begin{tabular}{cccccc}
\hline Index & Characteristic & $\mathbf{p H}$ & $\begin{array}{c}\text { COD } \\
(\mathbf{m g} / \mathrm{L})\end{array}$ & $\begin{array}{c}\text { TP } \\
\text { (mg/L) }\end{array}$ & $\begin{array}{c}\text { Chroma } \\
\text { (time) }\end{array}$ \\
\hline Value & $\begin{array}{c}\text { Light yellow, transparent, and } \\
\text { no pungent odor }\end{array}$ & 8.1 & 78.6 & 5.2 & 32.0 \\
\hline
\end{tabular}

\subsection{Coagulation and Catalytic Oxidation Experiment}

The steps of the coagulation experiment are presented as follows: Weigh a certain amount of coagulant using an electronic balance (AL104; Sartorius Scientific Instrument Co., Ltd.; Beijing, China). Place the weighed coagulant $(20 \mathrm{~g} / 100 \mathrm{~mL})$ in pure water and then mix with a magnetic stirrer at a constant temperature to dissolve (85-2A; Boyuan Experimental Analysis Instrument Factory; Changzhou, China). Prepare the solutions with different concentrations. Set the coagulation test mixer (ZR4-6; Zhongrun Water Industrial Technology Development Co., Ltd.; Shenzhen, China) at a certain speed and rotation time. Place the beaker with an appropriate amount of wastewater in the mixer to stir and then add the prepared coagulant solution. For the $\mathrm{pH}$ adjustment in the experiment, use $1 \mathrm{~mol} / \mathrm{L}$ $\mathrm{HCl}$ or $1 \mathrm{~mol} / \mathrm{L} \mathrm{NaOH}$, and observe the $\mathrm{pH}$ value using a $\mathrm{pH}$ meter (PHB-4; Dazhong Analytical Instrument Factory; Shanghai, China). After the completed stirring reaction and standing for $10 \mathrm{~min}$, extract the supernatant to measure the values of COD, TP, and chromaticity and observe the changes in floc morphology and water color.

The experimental steps of ozone catalytic oxidation are presented as follows: Connect an oxygen bottle, ozone generator (CF-G-3-010g; Guolin Environmental Protection Technology Co., Ltd.; Qingdao, China), columnar plexiglass reactor, and gas cylinder, in this order. Attach the gas outlet pipe of the ozone generator to the aeration disk at the bottom of the reactor and connect the gas outlet at the upper part of the reactor to the gas cylinder containing the KI solution. Extract a certain volume of water sample after the coagulation treatment, and then pour the water sample into the laboratory-made cylindrical plexiglass reactor. Seal the reactor after pouring the laboratory-made catalyst and the prepared $\mathrm{H}_{2} \mathrm{O}_{2}$ solution in the electronic balance into the reactor. Activate the power to generate ozone gas and open the oxygen cylinder valve. After a period of reaction, deactivate the instrument and extract the water sample to determine the water quality. 
TP was measured using an ultraviolet spectrophotometer (UV2600; Shimadzu Corporation; Kyoto, Japan). Chromaticity was determined following the national standard (GB11903-89). COD was measured on a Hach COD analyzer (DR1010, HACH, Loveland, CO, USA) using potassium dichromate.

\section{Conclusions}

In this study, coagulation-coupled ozone catalytic oxidation is used to treat phosphoruscontaining pesticide wastewater thoroughly. The remaining amount of TP is only $0.68 \mathrm{mg} / \mathrm{L}$ at the optimal coagulation condition, and PAFS has an advantage in removing TP. After coagulation, the remaining amounts of COD and chroma are $64.8 \mathrm{mg} / \mathrm{L}$ and 16 , respectively. The effluent after coagulation is then subjected to ozone catalytic oxidation treatment. Under the optimal conditions of ozone catalytic oxidation, the removal efficiency of the final effluent COD and chromaticity is significantly improved by $60.4 \%$ and $25.0 \%$, respectively, compared with coagulation alone. Compared with coagulation, ozone catalytic oxidation can easily remove refractory organics and effectively reduce the COD and color of wastewater. Charge neutralization and adsorption bridging are the primary mechanisms of action in the process of PAFS treatment of phosphorus-containing wastewater. Ozone and $\mathrm{H}_{2} \mathrm{O}_{2}$ have a synergistic effect on the ozone catalytic oxidation reaction. The self-made catalyst accelerates the catalytic reaction, promotes the production of additional hydroxyl radicals, and improves the removal efficiency of organic matter with poor biodegradability. Therefore, in the treatment of phosphorus-containing pesticide wastewater, the coagulation-coupled ozone catalytic oxidation process has good development prospects.

Author Contributions: Conceptualization, S.C., M.Z., A.L., Y.S., L.C. and M.W.; methodology, S.C., Y.S., L.C.; software, S.C. and M.Z.; validation, A.L. and M.W.; formal analysis, A.L. and M.W.; investigation, A.L., M.W., Y.S., L.C.; resources, S.C., A.L. and M.W.; data curation, A.L. and M.W.; writing-original draft preparation, Y.S., L.C.; writing-review and editing, Y.S., L.C.; visualization, A.L. and M.W.; supervision, S.C., Y.S., L.C.; project ad-ministration, S.C., Y.S., L.C.; funding acquisition, S.C., Y.S., L.C. All authors have read and agreed to the published version of the manuscript.

Funding: This research received no external funding.

Data Availability Statement: Data is contained within the article.

Conflicts of Interest: The authors declare no conflict of interest.

\section{References}

1. Altinok, I.; Capkin, E.; Karahan, S.; Boran, M. Effects of water quality and fish size on toxicity of methiocarb, a carbamate pesticide, to rainbow trout. Environ. Toxicol. Pharmacol. 2006, 22, 20-26. [CrossRef]

2. Fischer, A.; Wezel, A.P.; Hollender, J.; Cornelissen, E.; Hofman, R.; van der Hoek, J.P. Development and application of relevance and reliability criteria for water treatment removal efficiencies of chemicals of emerging concern. Water Res. 2019, 161, $274-287$. [CrossRef] [PubMed]

3. Asif, M.B.; Fida, Z.; Tufail, A.; van de Merwe, J.P.; Leusch, F.; Pramanik, B.K.; Price, W.E.; Hai, F.I. Persulfate oxidation-assisted membrane distillation process for micropollutant degradation and membrane fouling control. Sep. Purif. Technol. 2019, 222, 321-331. [CrossRef]

4. Kanan, S.; Moyet, M.A.; Arthur, R.B.; Patterson, H.H. Recent advances on $\mathrm{TiO}_{2}$-based photocatalysts toward the degradation of pesticides and major organic pollutants from water bodies. Catal. Rev. 2020, 62, 1-65. [CrossRef]

5. Barba, S.; Carvela, M.; Villasenor, J.; Rodrigo, M.A.; Canizares, P. Fixed-bed biological barrier coupled with electrokinetics for the in situ electrobioremediation of 2,4-dichlorophenoxyacetic acid polluted soil. J. Chem. Technol. Biotechnol. 2019, 94, $2684-2692$. [CrossRef]

6. Ul Haq, A.; Usman, M.; Muneer, M.; Maqbool, T.; Khosa, M.; Abbas, N. Performance and mechanism of removal of atrazine pesticide from aqueous media utilizing pumpkin seeds shell powder. Desalin. Water Treat. 2019, 160, 229-239. [CrossRef]

7. Sun, W.; Sun, Y.; Zhu, H.; Zheng, H. Catalytic activity and evaluation of Fe-Mn@Bt for ozonizing coal chemical biochemical tail water. Sep. Purif. Technol. 2020, 239, 116524. [CrossRef]

8. Sun, W.; Sun, Y.; Shah, K.J.; Zheng, H.; Ma, B. Electrochemical degradation of oxytetracycline by Ti-Sn-Sb/ $\gamma-\mathrm{Al} 2 \mathrm{O} 3 \mathrm{three}-$ dimensional electrodes. J. Environ. Manag. 2019, 241, 22-31. [CrossRef] [PubMed]

9. Pasupuleti, R.R.; Tsai, P.C.; Ponnusamy, V.K. A fast and sensitive analytical procedure for monitoring of synthetic pyrethroid pesticides' metabolites in environmental water samples. Microchem. J. 2019, 148, 355-363. [CrossRef] 
10. Ramya, K.; Vasudevan, N. Performance evaluation of ETP from pesticide manufacturing industry by using WWQI and multivariate statistical analysis. Environ. Sci. Pollut. Res. 2019, 26, 20595-20609. [CrossRef]

11. Ramon, F.; Lull, C. Legal measures to prevent and manage soil contamination and to increase food safety for consumer health: The case of Spain. Environ. Pollut. 2019, 250, 883-891. [CrossRef] [PubMed]

12. Edwards, Q.A.; Sultana, T.; Kulikov, S.M.; Garner-O'Neale, L.D.; Metcalfe, C.D. Micropollutants related to human activity in groundwater resources in Barbados, West Indies. Sci. Total Environ. 2019, 671, 76-82. [CrossRef]

13. Aydin, S.; Aydin, M.E.; Beduk, F.; Ulvi, A. Removal of antibiotics from aqueous solution by using magnetic Fe $\mathrm{O}_{4} / \mathrm{red}_{\mathrm{mud}}$ nanoparticles. Sci. Total Environ. 2019, 670, 539-546. [CrossRef] [PubMed]

14. Yasar, A.; Ghaffar, A.; Mahfooz, Y.; Tabinda, A.B.; Mehmood, A. Comparative performance evaluation of ozone oxidation and coagulation for the treatment of electroplating wastewater. Desalin. Water Treat. 2021, 230, 268-275. [CrossRef]

15. Zheng, H.; Sun, Y.; Zhu, C.; Guo, J.; Zhao, C.; Liao, Y.; Guan, Q. UV-initiated polymerization of hydrophobically associating cationic flocculants: Synthesis, characterization, and dewatering properties. Chem. Eng. J. 2013, 234, 318-326. [CrossRef]

16. Yang, X.; Zhang, L.; Jin, X.; Liu, L.; Zhang, Y.; Ni, Q.; Yao, J. Synthesis of hydrophobically modified cellulose-based flocculant and its application in treatments of kaolin suspension and machining wastewater. Cellulose 2017, 24, 5639-5647. [CrossRef]

17. Zhang, F.; Wu, K.; Zhou, H.; Hu, Y.; Sergei, P.; Wu, H.; Wei, C. Ozonation of aqueous phenol catalyzed by biochar produced from sludge obtained in the treatment of coking wastewater. J. Environ. Manag. 2018, 224, 376-386. [CrossRef] [PubMed]

18. Sun, Y.; Ren, M.; Zhu, C.; Xu, Y.; Zheng, H.; Xiao, X.; Wu, H.; Xia, T.; You, Z. UV-Initiated graft copolymerization of cationic Chitosan-Based flocculants for treatment of zinc Phosphate-Contaminated wastewater. Ind. Eng. Chem. Res. 2016, 55, 10025-10035. [CrossRef]

19. Sun, Y.; Li, P.; Zheng, H.; Zhao, C.; Xiao, X.; Xu, Y.; Sun, W.; Wu, H.; Ren, M. Electrochemical treatment of chloramphenicol using $\mathrm{Ti}-\mathrm{Sn} / \gamma-\mathrm{Al}_{2} \mathrm{O}_{3}$ particle electrodes with a three-dimensional reactor. Chem. Eng. J. 2017, 308, 1233-1242. [CrossRef]

20. Chen, W.; Zheng, H.; Zhai, J.; Wang, Y.; Xue, W.; Tang, X.; Zhang, Z.; Sun, Y. Characterization and coagulation-flocculation performance of a composite coagulant: Poly-ferric-aluminum-silicate-sulfate. Desalin. Water Treat. 2015, 56, 1776-1786. [CrossRef]

21. Sun, Y.; Zhu, C.; Zheng, H.; Sun, W.; Xu, Y.; Xiao, X.; You, Z.; Liu, C. Characterization and coagulation behavior of polymeric aluminum ferric silicate for high-concentration oily wastewater treatment. Chem. Eng. Res. Des. 2017, 119, 23-32. [CrossRef]

22. Sun, Y.; Zhu, C.; Sun, W.; Xu, Y.; Xiao, X.; Zheng, H.; Wu, H.; Liu, C. Plasma-initiated polymerization of chitosan-based CS-gP(AM-DMDAAC) flocculant for the enhanced flocculation of low-algal-turbidity water. Carbohydr. Polym. 2017, 164, 222-232. [CrossRef] [PubMed]

23. Danesh, S.; Oleszkiewicz, J.A. Volatile fatty acid production and uptake in biological nutrient removal systems with process separation. Water Environ. Res. 1997, 69, 1106-1111. [CrossRef]

24. Piazza, G.J.; Lora, J.H.; Wayman, L.I.; Garcia, R.A. Removal of lignin from straw spent pulping liquor using synthetic cationic and biobased flocculants. Sep. Purif. Technol. 2017, 188, 348-357. [CrossRef]

25. Konduri, M.K.R.; Fatehi, P. Influence of $\mathrm{pH}$ and ionic strength on flocculation of clay suspensions with cationic xylan copolymer. Colloids Surf. A 2017, 530, 20-32. [CrossRef]

26. Lu, X.; Xu, Y.; Sun, W.; Sun, Y.; Zheng, H. UV-initiated synthesis of a novel chitosan-based flocculant with high flocculation efficiency for algal removal. Sci. Total Environ. 2017, 609, 410-418. [CrossRef] [PubMed]

27. Zhang, Z. The flocculation mechanism and treatment of oily wastewater by flocculation. Water Sci. Technol. 2017, 76, 2630-2637. [CrossRef]

28. Sun, J.; Ma, X.; Li, X.; Fan, J.; Chen, Q.; Liu, X.; Pan, J. Preparation of a cationic polyacrylamide (CPAM) and its flocculation performance in the environmental estrogen removal and separation. Desalin. Water Treat. 2017, 100, 231-242. [CrossRef]

29. You, Z.; Zhuang, C.; Sun, Y.; Zhang, S.; Zheng, H. Efficient removal of $\mathrm{TiO}_{2}$ nanoparticles by enhanced flocculation-coagulation. Ind. Eng. Chem. Res. 2019, 58, 14528-14537. [CrossRef]

30. Chen, L.; Zhu, H.; Sun, Y.; Chiang, P.; Sun, W.; Xu, Y.; Zheng, H.; Shah, K.J. Characterization and sludge dewatering performance evaluation of the photo-initiated cationic flocculant PDD. J. Taiwan Inst. Chem. Eng. 2018, 93, 253-262. [CrossRef]

31. Zhang, Z.; Nong, H.; Zhao, L.; Zhang, H. A particle size distribution analysis method to quantitatively evaluate coagulation of fine particles in aqueous solutions. Part. Sci. Technol. 2018, 36, 771-777. [CrossRef]

32. Chen, L.; Sun, Y.; Sun, W.; Shah, K.J.; Xu, Y.; Zheng, H. Efficient cationic flocculant MHCS-g-P(AM-DAC) synthesized by UV-induced polymerization for algae removal. Sep. Purif. Technol. 2019, 210, 10-19. [CrossRef]

33. Sun, Y.; Shah, K.J.; Sun, W.; Zheng, H. Performance evaluation of chitosan-based flocculants with good pH resistance and high heavy metals removal capacity. Sep. Purif. Technol. 2019, 215, 208-216. [CrossRef]

34. Sun, Y.; Chen, A.; Pan, S.; Sun, W.; Zhu, C.; Shah, K.J.; Zheng, H. Novel chitosan-based flocculants for chromium and nickle removal in wastewater via integrated chelation and flocculation. J. Environ. Manag. 2019, 248, 109241. [CrossRef] [PubMed]

35. Ding, Y.; Wang, J.; Xu, S.; Lin, K.A.; Tong, S. Oxygen vacancy of $\mathrm{CeO}_{2}$ improved efficiency of $\mathrm{H}_{2} \mathrm{O}_{2} / \mathrm{O}_{3}$ for the degradation of acetic acid in acidic solutions. Sep. Purif. Technol. 2018, 207, 92-98. [CrossRef]

36. Ahmadi, M.; Rahmani, H.; Takdastan, A.; Jaafarzadeh, N.; Mostoufi, A. A novel catalytic process for degradation of bisphenol a from aqueous solutions: A synergistic effect of nano- $\mathrm{Fe}_{3} \mathrm{O}_{4} @ \mathrm{Alg}-\mathrm{Fe}$ on $\mathrm{O}_{3} / \mathrm{H}_{2} \mathrm{O}_{2}$. Process Saf. Environ. 2016, 104, 413-421. [CrossRef]

37. Sun, Y.; Zhou, S.; Sun, W.; Zhu, S.; Zheng, H. Flocculation activity and evaluation of chitosan-based flocculant CMCTS-g-P(AMCA) for heavy metal removal. Sep. Purif. Technol. 2020, 241, 116737. [CrossRef] 
38. Peng, R.; Shen, T.; Tong, S.; Ma, C. An effective heterogeneous Ozone-Based advanced oxidation process in acidic solution-TiMCM-41/ $\mathrm{H}_{2} \mathrm{O}_{2} / \mathrm{O}_{3}$. Ozone-Sci. Eng. 2016, 38, 194-202. [CrossRef]

39. Sun, Y.; Sun, W.; Shah, K.J.; Chiang, P.; Zheng, H. Characterization and flocculation evaluation of a novel carboxylated chitosan modified flocculant by UV initiated polymerization. Carbohydr. Polym. 2019, 208, 213-220. [CrossRef]

40. Liang, J.; Ning, X.; Sun, J.; Song, J.; Hong, Y.; Cai, H. An integrated permanganate and ozone process for the treatment of textile dyeing wastewater: Efficiency and mechanism. J. Clean. Prod. 2018, 204, 12-19. [CrossRef]

41. Liu, C.; Chen, X.; Zhang, J.; Zhou, H.; Zhang, L.; Guo, Y. Advanced treatment of bio-treated coal chemical wastewater by a novel combination of microbubble catalytic ozonation and biological process. Sep. Purif. Technol. 2018, 197, 295-301. [CrossRef]

42. Sun, W.; Zhou, S.; Sun, Y.; Xu, Y. Synthesis and evaluation of cationic flocculant P(DAC-PAPTAC-AM) for flocculation of coal chemical wastewater. J. Environ. Sci.-China 2021, 99, 239-248. [CrossRef] [PubMed]

43. Lumeau, J.; Glebova, L.; Glebov, L.B. Absorption and scattering in photo-thermo-refractive glass induced by UV-exposure and thermal development. Opt. Mater. 2014, 36, 621-627. [CrossRef]

44. Raeisivand, S.; Sadeghi, M.; Hemati, S.; Fadaei, A.; Sedehi, M.; Sadeghi, A.; Hoseini, S.M. Photocatalytic degradation of catechol in aqueous solutions: A comparison between $\mathrm{UV} / \mathrm{Fe}_{2} \mathrm{O}_{3}$ and $\mathrm{Fe}_{2} \mathrm{O}_{3}$ /sunlight processes. Desalin. Water Treat. 2019, 154, 340-346. [CrossRef]

45. Li, X.; Chen, W.; Ma, L.; Huang, Y.; Wang, H. Characteristics and mechanisms of catalytic ozonation with Fe-shaving-based catalyst in industrial wastewater advanced treatment. J. Clean. Prod. 2019, 222, 174-181. [CrossRef] 